\title{
Expression, purification and characterization of glycosylated influenza H5N1 hemagglutinin produced in Pichia pastoris
}

\author{
Edyta Kopera ${ }^{凶}$, Angela Dwornyk1, Piotr Kosson², Katarzyna Florys³, Violetta Sączyńska³, \\ Janusz Dębski1', Violetta Cecuda-Adamczewska3, Bogusław Szewczyk4, Włodzimierz Zagórski- \\ Ostoja ${ }^{1}$ and Krystyna Grzelak'
}

\begin{abstract}
IInstitute of Biochemistry and Biophysics Polish Academy of Sciences, Warsaw, Poland; ${ }^{2}$ Mossakowski Medical Research Centre Polish Academy of Sciences, Warsaw, Poland; ${ }^{3}$ nnstitute of Biotechnology and Antibiotics, Warsaw, Poland; ${ }^{4}$ Department of Recombinant Vaccines, Intercollegiate Faculty of Biotechnology, University of Gdansk and Medical University of Gdansk, Gdańsk, Poland
\end{abstract}

\begin{abstract}
The A/swan/Poland/305-135V08/2006 (H5N1-subtype) hemagglutinin (HA) gene was cloned and expressed in yeast Pichia pastoris ( $P$. pastoris). The HA cDNA lacking the C-terminal transmembrane anchor-coding sequence was fused to an a-factor leader peptide and placed under control of the methanol-inducible $P$. pastoris alcohol oxidase $1(A O X 1)$ promoter. Two $P$. pastoris strains: SMD 1168 and KM 71 were used for protein expression. Recombinant HA protein was secreted into the culture medium reaching an approximately $15 \mathrm{mg} / \mathrm{L}$ (KM 71 strain). Fusion protein with a $\mathrm{His}_{6}$ tag was purified to homogeneity in one step affinity chromatography. SDSPAGE and MS/MS analysis indicated that the protein is cleaved into HA1 and HA2 domains linked by a disulfide bond. Analysis of the $\mathrm{N}$-linked glycans revealed that the overexpressed HA is fully glycosylated at the same sites as the native HA in the vaccine strain. Immunological activity of the hemagglutinin protein was tested in mice, where rHA elicited a high immune response.
\end{abstract}

Key words: Avian influenza, H5N1, recombinant hemagglutinin, Pichia pastoris

Received: 02 June, 2014; revised: 19 July, 2014; accepted: 03 September, 2014; available on-line: 12 September, 2014

\section{INTRODUCTION}

Methylotrophic yeast Pichia pastoris efficiently expresses recombinant genes. Pichia has the following main advantages: (i) it is able to express heterologous genes in high yield (Romanos, 1995; Rodriguez et al., 1998), (ii) the proteins produced in this system may be secreted into the culture medium preserving correctly formed disulfide bonds (White et al., 1994). Additionally, P. pastoris secretes only a few other proteins to the medium which facilitates protein purification. (iii) The carbohydrate cores incorporated into the $\mathrm{N}$-glycosylation sites (Asn-X-Ser/Thr) of recombinant protein molecules are frequently at similar positions to those found in natural glycoproteins. Outer sugar of $P$. pastoris secreted proteins is Man8-10 GlcNAc2 (Grinna \& Tschopp, 1989). Efficiency of the $P$. pastoris expression system is based on an unusually strong promoter from the alcohol oxidase 1 gene $(A O X 1)$ driving the expression of the foreign gene. The AOX1 promoter is repressed in cells grown on glucose and most other carbon sources, but is induced over 1000-fold when cells are shifted to a medium containing methanol as a sole carbon source (Careghino et al., 2002). Nowadays, Pichia is widely accepted as an important biotechnological host organism. Various pharmacologically important proteins were produced in this expression system e.g: malaria vaccine antigen (Brady et al., 2001), human serum albumin (Bushell et al., 2003), IGF-1 (Brerley, 1998), insulin (Kjeldsen et al., 1999) and hepatitis B antigen (Cregg et al.,1987). This study is aimed at expression of the hemagglutinin (HA) gene of H5N1 avian influenza virus (AIV) in Pichia cells. The HA protein plays a crucial role in the virus infection. HA glycoprotein is synthesized as an inactive HA0 molecule assembled as noncovalently bound homotrimers on the viral surface. This precursor protein is cleaved (RRKKR/G multi-basic cleavage site for $\mathrm{H} 5$ subtype) by trypsin-like proteases to create two subunits, HA1 and HA2 which are linked by a single disulfide bond (Skehel \& Wiley, 2000). After cleavage, at the specific site, these two disulfide-bonded protein domains produce the mature form of the HA protein. Cleavage is a prerequisite for the infection. The HA0 molecule is post-translationally modified by glycosylation. Glycans are attached via N-glycosilic linkages to the asparagine residue of the conserved glycosylation site motif Asn-X-Ser/Thr (X-any amino acid) (Grinna \& Tschopp, 1989).

There are several strategies to develop a new generation of vaccines. One of the simplest is using the surface proteins of the virus. It was demonstrated that HA is the major target for the development of influenza vaccines (Crawford et al., 1999; Athmaram et al., 2011). In this report, we describe expression of the HA gene of H5N1 avian influenza virus in Pichia pastoris system. rHA was produced in a soluble form with high yield and was shown to be highly immunogenic in mice.

\section{MATERIALS AND METHODS}

Strain and plasmid vector. Two $P$. pastoris strains: KM 71 (his4, aox1::ARG4) and the protease deficient SMD 1168 (his4 and pep4), and the yeast expression $\mathrm{pPICZ} \alpha \mathrm{C}$ vector were obtained from Invitrogen.

Construction of $\mathrm{pPICZ} \alpha \mathrm{C} / \mathrm{HAHis}_{6}$ vector and transformation of Pichia pastoris. The IV strain H5N1

\footnotetext{
e-mail: ekopera@ibb.waw.pl
}

Abbreviations: HA, hemagglutinin; AOX, alcohol oxidase; Endo $\mathrm{H}$, endoglycosidase $H$, AIV, influenza virus. 
A/swan/Poland/305-135V08-2008 was the source of HA gene. The DNA fragment encoding HA protein lacking $16 \mathrm{~N}$-terminal aminoacids and C-terminal transmembrane anchor and cytoplasmic domain was amplified using forward and reverse primers containing ClaI and NotI restriction sites, respectively, and pGEM/HA as the template. The modified fragment codes for HA truncated peptide. Appropriate PCR fragment was inserted into $\mathrm{pPICZ} \alpha \mathrm{C}$ plasmid and introduced into $P$. pastoris strain KM73 or SMD 1168 by electroporation as described in the Invitrogen manual. Yeast transformants were also screened for the construct insertion at the alcohol oxidase promoter (AOX I) site by PCR, using 5 AOX I and 3' AOX I primers (Invitrogen).

Cell growth. Insert-positive yeast clones were grown initially in 100 or $400 \mathrm{ml}$ of BMGY medium (1\% yeast extract, $2 \%$ peptone, $100 \mathrm{mM}$ potassium phosphate, $\mathrm{pH}$ $6.0,1.34 \%$ yeast nitrogen base, $4 \times 10^{-5 \%}$ biotin, and $1 \%$ glycerol) at $30^{\circ} \mathrm{C}$ on a plate agitator at $160 \mathrm{rpm}$ agitation. When the culture reached $\mathrm{OD}_{600}$ of 2 , the cells were centrifuged at $3000 \times g$ for $5 \mathrm{~min}$ and resuspended in one/ fourth of the original volume of BMMY medium $(1 \%$ yeast extract, $2 \%$ peptone, $100 \mathrm{mM}$ potassium phosphate, $\mathrm{pH} 7.8,1.34 \%$ yeast nitrogen base, $4 \times 10^{-50} \%$ biotin, and $5 \%$ methanol) for induction of the AOX I promoter. Subsequent incubation at $26^{\circ} \mathrm{C}$ with vigorous shaking was continued for 5 or 7 days. The culture medium was cleared of yeast cells by centrifugation at $3000 \times g$ at $4^{\circ} \mathrm{C}$ for $6 \mathrm{~min}$ and the supernatant was collected for further HA purification.

Purification of His $_{6}$-rHA. Recombinant protein containing the hexahistidine tag was purified by affinity chromatography on Ni-NTA resin (Qiagen). $100 \mathrm{ml}$ of post culture medium aliquot was diluted to $200 \mathrm{ml}$ with a PBS buffer pH 7.4 containing $500 \mathrm{mM} \mathrm{NaCl}$ and gently mixed with $3 \mathrm{ml} \mathrm{Ni-NTA}$ resin at $4^{\circ} \mathrm{C}$ for $2.5 \mathrm{~h}$. The resin was packed into a column and washed with one volume of PBS buffer, then the bound protein was eluted with $3 \mathrm{ml}$ portions of the elution buffer $(250 \mathrm{mM}$ imidazole in PBS). Fractions containing protein were analyzed by SDS/PAGE and Western blotting. All fractions containing purified protein were pooled and dialyzed against PBS buffer pH 7.4. Subsequently the protein was lyophilized and stored at $-80^{\circ} \mathrm{C}$.

Western blotting. Proteins separated by $12 \%$ SDS/ PAGE were electrotransferred onto an Immobilon-P transfer membrane (Millipore). The membrane was incubated for $2 \mathrm{~h}$ with $5 \%$ non-fat dried milk in a TBS-T buffer (10 mM Tris/HCl, pH 8.0, $150 \mathrm{mM} \mathrm{NaCl}, 0.05 \%$ Tween 20). His $_{6}$-tagged HA protein was detected using a mouse monoclonal anti-His-HRP antibody (1:5000, Abcam). The membrane was analyzed using SuperSignal West Femto Trial Kit (Thermo Scientific). His 6 -tagged HA protein was also detected with monoclonal anti-HA1 antibody (a gift from the Institute of Biotechnology and Antibiotics, Warsaw). Alkaline phosphatase-conjucated anti-mouse antibody was used as a secondary antibody diluted at 1:30000 (Sigma-Aldrich). The blot was visualized with Western Blue Stabilized Substrate for alkaline phosphatase (Promega).

Determination of protein concentration. Protein concentration was determined according to the Bradford protocol. Bovine serum albumin was used as the standard.

Enzymatic deglycosylation. $5 \mu \mathrm{g}$ of $\mathrm{rHA}$ protein was denatured with 1x Glycoprotein Denaturizing Buffer at $95^{\circ} \mathrm{C}$ for $10 \mathrm{~min} .20 \mu \mathrm{l}$ of reaction mix containing denatured HA protein and $0.125 \mathrm{U}$ of endoglycosidase $\mathrm{H}$ (Endo H, NEB) in $1 \times$ G5 reaction buffer $(50 \mathrm{mM}$ so- dium citrate, $\mathrm{pH} 5.5$ ) was incubated at $37^{\circ} \mathrm{C}$ for $1 \mathrm{~h}$. An untreated protein sample was incubated under the same conditions without the enzyme.

MS/MS analysis of rHA. rHA protein after reaction with Endo $\mathrm{H}$ was analyzed by SDS/PAGE. A gel band containing deglycosylated polypeptides was excised. Protein was reduced with $100 \mathrm{mM}$ DT'T (for 30 minutes at $56^{\circ} \mathrm{C}$ ), alkylated with $0.5 \mathrm{M}$ iodoacetamide (45 min in a dark at room temperature) and digested overnight with $12.5 \mathrm{ng} / \mu \mathrm{l}$ of trypsin (sequencing Grade Modified Trypsin — Promega V5111) by adding the enzyme directly to the reaction mixture. Peptides were analyzed by LC-MSMS/MS (liquid chromatography coupled to tandem mass spectrometry) using Nano-Acquity (Waters) LC system and Orbitrap Velos mass spectrometer (Thermo Electron Corp.), by applying peptides to RP-18 precolumn (nanoACQUITY Symmetry ${ }^{\circledR}$ C18 — Waters 186003514) using water containing $0.1 \%$ TFA as a mobile phase and then transferred to nano-HPLC RP-18 column (nanoACQUITY BEH C18 - Waters 186003545) using an acetonitrile gradient (0-35\% AcN in 180 minutes) in the presence of $0.05 \%$ formic acid with the flow rate of $250 \mathrm{nl} / \mathrm{min}$. Column outlet was directly coupled to the ion source of the spectrometer working in the regime of data dependent MS to MS/MS switch. A blank run ensuring lack of cross contamination from previous samples preceded each analysis. Acquired raw data were processed by Mascot Distiller followed by Mascot Search (Matrix Science, London, UK, on-site license) against users' defined database. Search parameters for precursor and product ions mass tolerance were $40 \mathrm{ppm}$ and $0.8 \mathrm{Da}$, respectively, enzyme specificity: trypsin, missed cleavage sites allowed: 1 , fixed modification of cysteine by carbamidomethylation and variable modification of methionine oxidation and HexNAc at asparagine. Peptides with Mascot Score exceeding the threshold value corresponding to $<5 \%$ False Positive Rate, calculated by Mascot procedure were considered to be positively identified. Fragmentation spectra of peptides indicated by Mascot as N-glycosylated were manually investigated.

Immunization experiments. Seven-week old, pathogen-free, female Balb/c mice were used for vaccination. The animals were housed in a temperature controlled enviroment at $24^{\circ} \mathrm{C}$ with $12 \mathrm{~h}$ day-night cycles and received food and water ad libidum. Immunization experiments were done with groups consisting of 5 or 7 mice, in the animal house of Institute of Experimental Medicine PAS (Warsaw) under control of the Bioethics Committee (permission no 11/2012). In the first experiment mice were immunized three times intradermally in the hind paw at 3 -week intervals with $100 \mu \mathrm{l}$ containing 1 , 5 or $25 \mathrm{ug}$ of HA. An adequate portion of the protein was dissolved in saline plus adjuvant. For immunization, $25 \mu \mathrm{g}$ of Sigma Adjuvant System containing $0.5 \mathrm{mg} \mathrm{Mo}-$ nophosphoryl Lipid A (detoxified endotoxin) from Salmonella minnesota and $0.5 \mathrm{mg}$ synthetic Trehalose Dicorynomycolate in $2 \%$ oil (squalene)-Tween ${ }^{\circledR} 80$-water was used. Two booster injections were adjuvated with $25 \mu \mathrm{g}$ monophosphoryl lipid A and $25 \mu \mathrm{g}$ muramyl dipeptide (Sigma-Aldrich). Control mice received adjuvant only. One week prior to the first immunization and 2 weeks after each immunization, blood samples were collected, allowed to coagulate and centrifuged. The collected sera were stored at $-20^{\circ} \mathrm{C}$ before measuring the antibody level. In the second experiment, two different methods of administration were applied. Mice were immunized intradermally in the hind paw and subcutaneously in the neck with $100 \mu \mathrm{l}$ of $25 \mu \mathrm{g}$ rHA plus adjuvant. The immunization scheme was identical as in the first experiment. 
ELISA test. Sera from experimental animals were analyzed by indirect ELISA for detection of anti-HA IgG antibodies. The 96-well polystyrene plates (Nunc) were coated overnight at $4^{\circ} \mathrm{C}$ with recombinant $\mathrm{H} 5 \mathrm{HA}$ (17530, $\Delta 341-346,6 x$ His-tag at C-terminus) antigens: HA (A/Bar-headed Goose/Qinghai/12/05(H5N1)) produced in a mammalian cell system (Immune Technology) and HA (A/swan/Poland/305-135V08/2006(H5N1)) produced in a baculovirus system (Oxford Expression Technologies), diluted in PBS to $1 \mu \mathrm{g} / \mathrm{ml}$ for coating MaxiSorp wells (mouse trial 1) and $6 \mu \mathrm{g} / \mathrm{ml}$ for coating MediSorp wells (mouse trial 2), respectively. On the next day, plates were washed with PBST, blocked for $1.5 \mathrm{~h}$ with $2 \% \mathrm{BSA} / \mathrm{PBS}$ at $37^{\circ} \mathrm{C}$. Bound $\mathrm{IgG}$ were detected using goat anti-mouse IgG ( $\gamma$-chain specific)-HRP antibodies (Sigma-Aldrich). After incubation with TMB chromogen substrate solution (Sigma-Aldrich), absorbance was measured at $450 \mathrm{~nm}$ with a microplate reader (Synergy 2; Bio'Tek Instruments).

Hemagglutinin Inhibition (HI) test. Sera samples were heat inactivated at $56^{\circ} \mathrm{C}$ for $30 \mathrm{~min}$. and then were pretreated by kaolin and chicken erythrocytes to avoid a false positive reaction in the $\mathrm{HI}$ test (Bizanov \& Tamosiunas, 2005). The pretreated sera (25 $\mu \mathrm{l}$ of sera in serial twofold dilutions) were incubated for $25 \mathrm{~min}$ in a titration plate with $4 \mathrm{HA}$ units of the inactivated antigen (Bizanov and Tamosiunas, 2005). Next, the suspension of $1 \%$ hen's erythrocytes was added and incubated for $30 \mathrm{~min}$. The HI titer was determined as the reciprocal of the highest dilution in which hemagglutination is inhibited. Samples were assigned as positive when their titer was $\geq 16$. Sera from the immunization experiments (Trials 1 and 2) were tested using a heterologous strain H5N2 A/chicken/Belgium/150/1999 virus (GD Deventer).

Accession numbers. Sequences used in this study are available in public databases: H5N1 A/swan/ Poland/305-135V08/2006 (EpiFluDatabase [http://platform.gisaid.org], GenBank Accession No. EP1156789).

\section{RESULTS}

\section{Protein expression and purification}

In order to evaluate the potential of $P$. pastoris as an expression host for production of a recombinant influenza $\mathrm{H} 5$ hemagglutinin, the $\mathrm{pPICZ} \alpha \mathrm{C} / \mathrm{HAHis}_{6}$ vector was constructed. Template for amplifying the HA sequence was derived from H5N1 influenza virus (A/swan/ Poland/305-135V08/2006). Primers were designed to produce an anchor-free HA cDNA with extended ends that facilitated cloning and yielded a product containing the affinity tag. The amplified his- HA sequence fused to the heterologous $\alpha$-mating factor prepro-secretion signal form $S$. cerevisiae that directs protein export into the medium was ligated into appropriate restriction sites of the $\mathrm{pPICZ} \alpha \mathrm{C}$ plasmid. DNA sequencing confirmed correct orientation of the insert. Following amplification in the E. coli $\mathrm{DH} 5 \alpha$ strain, the $\mathrm{pPICZ}_{\alpha} \mathrm{C} / \mathrm{HAHis}_{6}$ plasmid was linearized with PmeI and used for transformation of P. pastoris KM71 and SMD 1168 strains. Expression of the HA gene was induced by the activation of $A O X 1$ promoter with methanol. P. pastoris transformants grown in the methanol-containing BMMY medium started to secrete the HA protein. Induction of $\mathrm{HA}$ was already visible after $24 \mathrm{~h}$, but was potentiated with time, an optimum being attained after 5-7 days. Figure 1 shows the rHA overexpression in a mean time of induction. SDS/
PAGE followed by Coomassie Brilliant Blue staining indicated that almost $90 \%$ of the overexpressed protein was secreted into the medium (not shown). Two P. pastoris strains were tested for protein expression and KM 71 strain yielded a higher protein level in comparison to that of SMD 1168 (15 $\mathrm{mg}$ and $9 \mathrm{mg}$ of total purified HA protein per liter, respectively). Therefore, this strain was selected for further optimization experiments. We observed a significant effect of the $\mathrm{pH}$ of the extracellular medium on the protein expression and the $\mathrm{pH} 7.8$ was selected for efficient protein production. In preliminary experiments, $1 \%$ methanol was added every $24 \mathrm{~h}$ until the optimal time of induction was reached. Further experiments have shown that a single induction with $5 \%$ methanol and 7 day cultivation after induction yielded the highest rHA level. For purification purposes P. pastoris shake-flask culture was scaled up to $400 \mathrm{ml}$ BMGY medium and $100 \mathrm{ml}$ of BMMY medium. The recombinant protein secreted into the culture medium was purified using affinity chromatography under native conditions. After one-step purification on the Ni-NTA resin the rHA protein was pure when analyzed by SDS/ PAGE (Fig. 2). Typically, 1.3-1.5 $\mathrm{mg}$ of recombinant antigen was obtained from $100 \mathrm{ml}$ of induced yeast-culture supernatant.

\section{Characterization of purified rHA}

The theoretical molecular weight of His-tagged HA lacking C-terminal transmembrane anchor and cytoplasmic domain is $59.5 \mathrm{kDa}$. The molecular weight of HA1 and HA2 domains is 39.5 and $20 \mathrm{kDa}$, respectively. SDS/PAGE analysis has shown that the rHA protein expressed in $P$. pastoris displayed three bands with molecular weight about 65,47 and 22 $\mathrm{kDa}$ (Fig. 2). Two of the higher molecular weight bands gave a positive signal in Western blot analysis using anti-His and anti-HA1 antibodies (Fig. 1A and B). Mass spectrometry analysis of protein bands confirmed the presence of the whole rHA and two cleaved subunits. In order to determine whether the
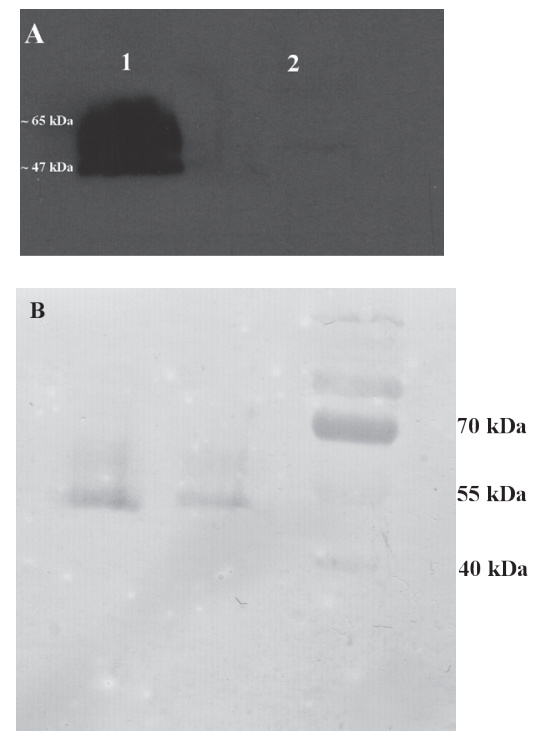

Figure 1. Western blot analysis of rHA overexpression.

Protein samples were electrophoresed in 12\% SDS/PAGE and transferred onto membrane and identified by anti-His $(\mathbf{A})$ and anti-HA1 (B) antibody. A - culture after $70 \mathrm{~h}$ of methanol induction. Line $1-1 \mathrm{ml}$ of culture medium precipitated with TCA. Line $2-$ cell pellet from $1 \mathrm{ml}$ of culture. B - Ni-NTA column purified rHA, line 1 and $2-$ about $2 \mu \mathrm{g}$ of protein eluted consecutively from column by $250 \mathrm{mM}$ imidazole. $\mathrm{M}$ - protein marker. 


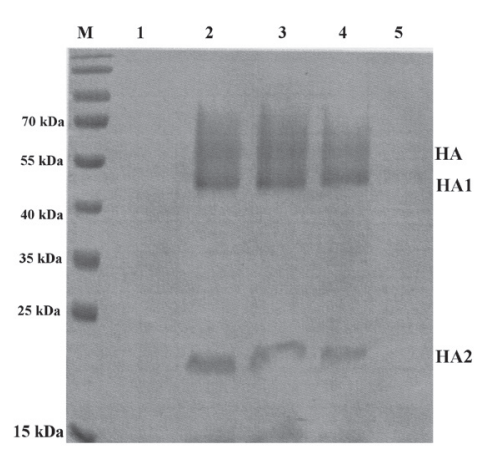

Figure 2. Purification of rHA by Ni-NTA chromatography. $\mathrm{M}$ - protein marker, Lane 1 - wash with PBS, Lane 2 to 5 protein eluted with $250 \mathrm{mM}$ imidazole.

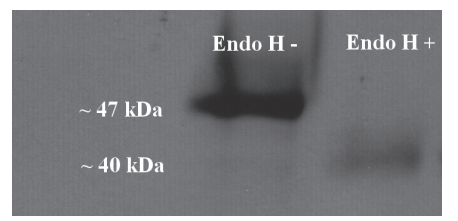

Figure 4. Western blot analysis of rHA1 treated with Endo $\mathrm{H}$. rHA purified from $P$. pastoris KM 71 strain was deglycosylated with Endo $\mathrm{H}$.

Protein samples were electrophoresed in $12 \%$ SDS/PAGE and transferred onto membrane and identified by anti-His ant/ibody.

rHA protein is partially cleaved into HA1 and HA2 subunits, an excess of a reducing agent was added to the elution fractions. Under reducing conditions only two bands: about 47 and $22 \mathrm{kDa}$ were seen, indicating that the whole pool of rHA expressed in $P$. pastoris is cleaved into HA1 and HA2 subunits (Fig. 3).

\section{MS/MS analysis of protein}

The difference between the calculated molecular weight of rHA and its subunits and the apparent molecular weight of SDS/PAGE bands indicated protein modifications. After a reaction with Endo $\mathrm{H}$, the molecular weight of about $47 \mathrm{kDa}$ band decreased to about $40 \mathrm{kDa}$ (Fig. 4). This shift in molecular weight suggests glycosylation of the rHA protein produced in $P$. pastoris. Mass spectrometry analysis confirmed that all of the predicted glycosylation sites in HA1 subunit are glycosylated (see Table 1).

\section{Glycosylated and truncated rHA elicits a high antibody titer}

Purified, His-tagged hemagglutinin was tested for immunogenicity in a mice model. To determine an optimal dose of the antigen, mice were immunized intradermally with three doses of rHA given at 3-week intervals. A control group received only adjuvant at the same intervals and it did not induce an HA-spe-

Table 1. Table represents $\mathrm{N}$-glycosylated peptides from the HA of H5N1 influenza strain (A/swan/Poland/305-135V08/2006) confirmed by LC/MS analysis.

$\mathrm{N}$-linked glycosylation sites are underlined and in bold. In case of 1-22 peptide, two neighboring asparagine residues are modified.

\begin{tabular}{llll}
\hline Glycosite & Residue & Region & Amino acid sequence \\
\hline 1 & $1-22$ & HA1 & HANNSTEQVDTIMEK \\
\hline 2 & $22-35$ & HA1 & NVTVTHAQDILEK \\
\hline 3 & $163-189$ & HA1 & SYNNTNQEDLLVLWGIHHPNDAAEQTR \\
\hline 4 & $278-304$ & HA1 & CQTPIGAINSSMPF \\
\hline
\end{tabular}

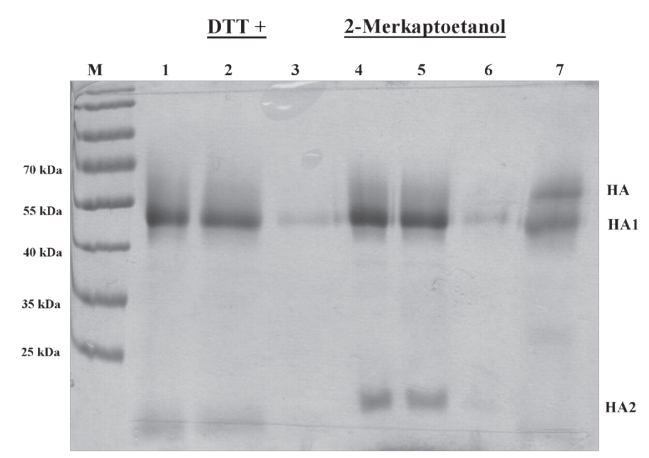

Figure 3. Electrophoretic analysis of rHA protein under reducing and non-reducing conditions.

cific immune response. After the second, and more clearly, after the third antigen injection, a significant immune response was detected in mice immunized with 1,5 and $25 \mu \mathrm{g}$ of $\mathrm{rHA}$ (Fig. 5A). Sera samples of mice immunized with the lowest antigen dose $(1 \mu \mathrm{g})$ show the highest $\operatorname{IgG}$ titer reached ca. $1 \mathrm{mln}$ after the second booster, however, with a significant scatter. Not surprisingly, the individual response seems to normalize with higher antigen doses, i.e. $25 \mu \mathrm{g}$. Therefore, the next immunization series were done with an elevated antigen concentration. Titer in the HI assay was considered as a preliminary and indirect measure of neutralizing antibody response against the rHA antigen. Group immunized with $1 \mu \mathrm{g}$ of $\mathrm{rHA}$ showed a maximum of $512 \mathrm{HI}$ titer but only 3 mice out of 5 were positive. To explore whether the route of immunization affected the efficacy of humoral response in mice, the animals were immunized intradermally and subcutaneously with $25 \mu \mathrm{g}$ of rHA. After third immunization, mice immunized subcutaneously showed a higher IgG titer (Fig. 5B).

\section{DISCUSSION}

Influenza virus is a pathogen inducing respiratory disease with symptoms varying from mild to severe. Certain strains of the virus could be even lethal to the host. The virus recurring epidemics, quite often evolving into pandemics, are a constant menace to public health. Besides humans, the virus spreads among swine, horses, and dogs, but mainly in birds, often pointed out as the primary host of the pathogen. Until now, there are no safe medications against influenza. Effectiveness of a quite recently introduced drug — tami$\mathrm{flu}$ - is under discussion, and the strains resistant to the drug already circulate in the population. A realistic barrier against the disease remains therefore by vaccination against influenza. It is well established that the virus' hemagglutinin is the main antigen, inducing neutralizing antibodies. However, the HA gene mutates fast and the resulting "antigenic drift" necessities constant creation of novel vaccine versions acting against seasonal versions of the pathogen. This is a rather compelling task as the standard vaccines are prepared from the viruses grown on a large scale in chicken embryos. Production of the recombinant $\mathrm{HA}$ in appropriate expression systems is an alternative approach. Some of such systems were already successfully adapted to production of a recombinant 
A

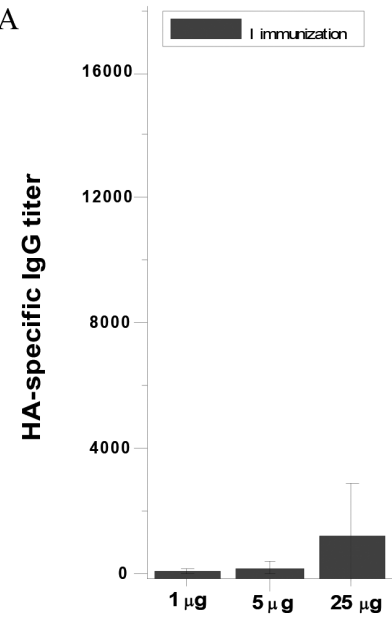

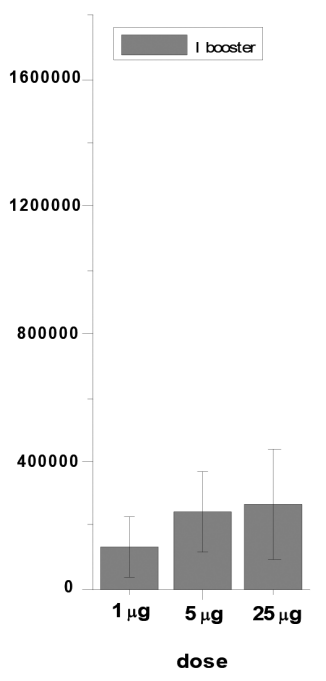

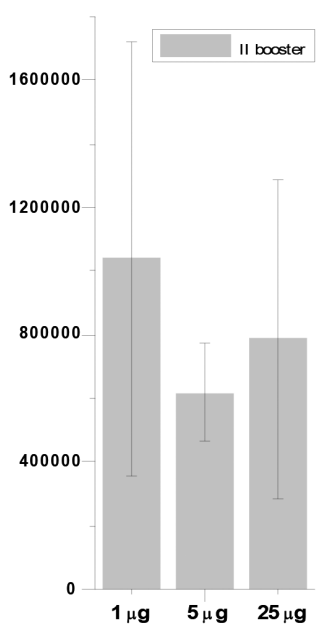

B
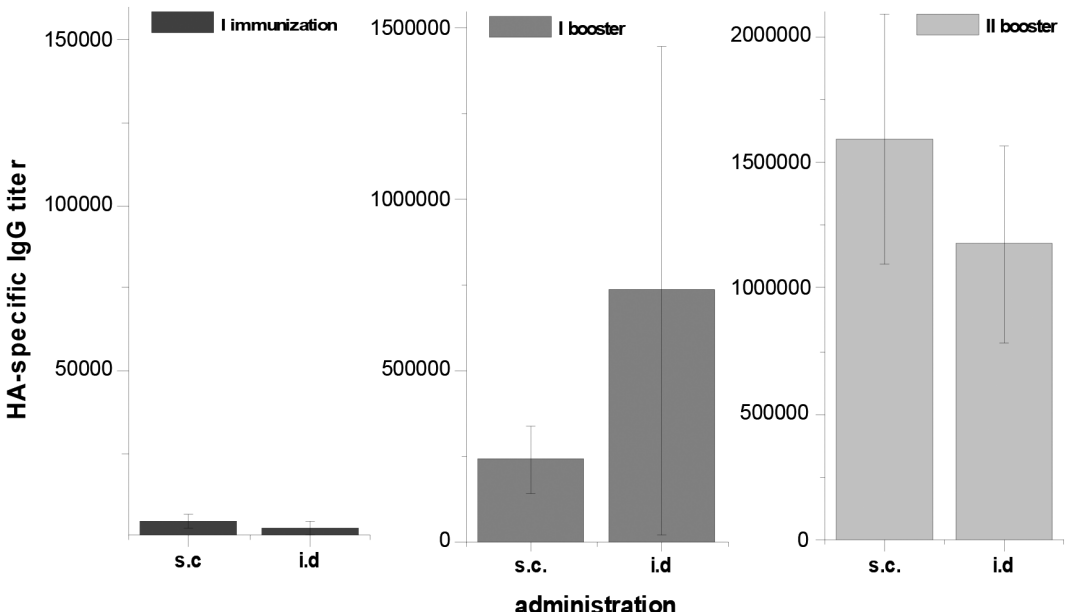

Figure 5. A. HA specific serum IG endpoint titers after mice immunization with $P$. pastoris rHA.

Bars represent the average of the titers in sera collected separately from 5 individuals. For each bar, the range of scattering is indicated. The endpoint titer is defined as the highest dilution of serum yielding in ELISA test absorbance 4 times over background. B. Evaluation of the route of antigen administration. Mice were injected with $25 \mu \mathrm{g}$ doses of rHA antigen either subcutaneously (s.c) or intradermally (i.d.).

antigen, useful as a so called "subunit" or "new generation" vaccine, but have some disadvantages. Production in mammalian or insect cell lines (Wu et al., 2010; Crawford et al., 1999) is costly, requires high-tech mass cell production that is under constant threat of foreign pathogen introduction. HA may be overexpresessed in E.coli, but the product is insoluble and the purification is tedious. Searching for an optimal antigen production method we opted for a simple and inexpensive Pichia pastoris system. Here, secretion of the overexpressed polypeptide considerably facilitates the purification of the product. In the literature, there are reported several attempts at the production of $\mathrm{HA}$ in $P$. pastoris. Full length HA protein of H1 type (Athmaram et al., 2011; 2012) and H5 type virus (Wang et al., 2007) were expressed in P. pastoris as partially secreted, soluble proteins. The level of expressions appeared to be low. Expression of the H5 type polypeptide was also reported by the Subathra group (Subathra et al., 2014) but the protein was not exported out of the cells. In the system described here, the overproduced protein is secreted up to at least $90 \%$, considerably facilitating further purification of the antigen. We anticipated that such efficient secretion results from the truncation of the sequence coding for $16 \mathrm{~N}$-terminal amino acids (signal peptide) and the C-terminal transmembrane domain. This HA fragment is responsible for anchoring in the cell membrane and its deletion may be beneficial for secretion. Our selection of an appropriate producer strain is also advantageous. Contrary to the common observations, it is not the standard SMD 1168 secreting strain, but KM 71 which efficiently secretes the HA antigen. This is surprising as in our previous experiments with expression of several polypeptides, SMD 1168 appeared to be an efficient secretion strain (Grzelak et al., 2003; Kludkiewicz et al., 2005). An important factor for activity of HA is its specific cleavage into $\mathrm{H} 1$ and $\mathrm{H} 2$ subunits (Klenk et al., 1975; Lazarowitz \& Choppin, 1975; Steinhauer, 1999). In contrast to other reports (Wang et al., 2007) the rHA produced in our system is fully processed into subunits, without traces of further proteolysis (see Fig. 2). The data presented here demon- 
strate that the influenza antigen produced in $P$. pastoris with good efficiency is highly immunogenic and might be consider as a candidate for a subunit vaccine.

\section{Acknowledgements of financial support}

This work was supported by Innovative Economy Program, Grant No. WND-POIG.01.01.02-00-007/08.

\section{REFERENCES}

Athmaram T, Saraswat S, Santhosh S, Singh AK, Suryanarayana V, Priva R, Gopalan N, Parida M, Lakshmana RP, Vijayaraghavan R (2011) Yeast expressed recombinant hemagglutinin protein of novel H1N1 elicits neutralizing antibodies in rabbits and mice. Virology $J$ 8: 524 .

Athmaram TN, Saraswat S, Singh AK, Rao MK, Gopalan N, Suryanarayana VV, Rao PV (2012) Influence of copy number on the expression levels of pandemic influenza hemagglutinin recombinant protein in methylotrophic yeast Pichia pastoris. Virus Genes 45: 440-451.

Bizanov G, Tamosiunas V (2005) Immune response induced In mice after intragastral administration with Sendai virus In combination with extract of Uncaria Tomentosa. Scand J Lab Anim Sci 32: 201-207.

Brady CP, Shimp RL, Miles AP, Whitmore M, Stowers AW (2001) High-level production and purification of P30P2MSP1(19), an important vaccine antigen for malaria, expressed in the methylotropic yeast Pichia pastoris. Protein Expr Purif 23: 468-475.

Brierley RA (1998) Secretion of recombinant human insulin-like growth factor (IGF-1). Methods Mol Biol 103: 149-177.

Bushell ME, Rowe M, Avignone-Rossa CA, Wardell JN (2003) Cyclic fed-batch culture for production of human serum albumin in Pichia pastoris. Biotechnol Bioeng 82: 678-683.

Cereghino GPL, Cereghino JL, IIgen C, Cregg JM (2002) Production of recombinant proteins in fermenter cultures of the yeast Pichia pastoris. Curr Opin Biotechnol 13: 329-332.

Crawford J, Wilkinson B, Vosnesensky A, Smith G, Garcia M, Stone H, Perdue ML (1999) Baculovirus-derived hemagglutinin vaccines protect against lethal influenza infections by avian $\mathrm{H} 5$ and $\mathrm{H} 7$ subtypes. Vaccine 17: 2265-2274.
Grinna LS, Tschopp JF (1989) Size distribution and general structural features of $\mathrm{N}$-linked oligosaccharides from the methylotrophic yeast Pichia pastoris. Yeast 5: 107-115.

Grzelak K, Kłudkiewicz B, Kolomiets IL, Dębski J, Dadlez M, Lalik A, Ożyhar A, Kochman M (2003) Overexpression of juvenile hormone Winding protein In bacteria and Pichia pastoris. Protein Expr Purif 31: 173-180.

Kjeldsen T, Pettersson AF, Hach M (1999) Secretory expression and characterization of insulin in Pichia pastoris. Biotechnol Appl Biochem 29: 79-86.

Klenk HD, Rott R, Orlich M, Blödorn J (1975) Activation of influenza A viruses by trypsin treatment. Virology 68: 426-439.

Kłudkiewicz B, Kodrik D, Grzelak K, Nirmala X, Sehnal F (2005) Structurally unique recombinant Kazal-type proteinase inhibitor retains activity when terminalny extender and glycosylated. Protein Expr Purif 43: 94-102.

Lazarowitz SG, Choppin PW (1975) Enhancement of the infectivity of influenza $\mathrm{A}$ and $\mathrm{B}$ viruses by proteolytic cleavage of the hemagglutinin polypeptide. Virology 68: 440-454.

Rodriquez M, Martinez V, Alazo K, Suarez M, Redondo M, Montero C, Besada V, de la Fuente J (1998) The bovine IFN-omega 1 is biologically active and secreted at high levels in the yeast Pichia pastoris. J Biotechnol 60: 3-14.

Romanos MA (1995) Advances in the use of Pichia pastoris for highlevel gene expression. Curr Opin Biotechnol 6: 527-533.

Skehel JJ, Wiley DC (2000) Receptor binding and membrane fusion in virus entry: the influenza hemagglutinin. Annu. Rev Biochem 69: $531-569$.

Steinhauer DA (1999) Role of hemagglutinin cleavage for the pathogenicity of influenza virus. Virology 258: 1-20.

Subathra M, Santhakumar P, Narasu ML, Beevi SS, Lal SK (2014) Evaluation of antibody response in mice against avian influenza A (H5N1) strain neuraminidase expressed in yeast Pichia pastoris. J Biosci 39: 443-451.

Wang CY, Luo YL, Chen YT, Li SK, Lin CH, Hsieh YC, Liu HJ (2007) The cleavage of the hemagglutinin protein of $\mathrm{H} 5 \mathrm{~N} 2$ avian influenza virus in yeast. J Virol Methods 146: 293-297.

White CE, Kempi NM, Komives EA (1994) Expression of highly disulfide-bonded proteins in Pichia pastoris. Structure 2: 1003-1005.

Wu CY1, Yeh YC, Yang YC, Chou C, Liu MT, Wu HS, Chan JT, Hsiao PW (2010) Mammalian expression of virus-like particles for advanced mimicry of authentic influenza virus. PLoS One 5: e9784. 